\title{
Prevalence of insomnia in urban population of West Bengal: A community-based cross-sectional study
}

$\pi$
0
0
0
5
0
$\frac{1}{4}$

\section{Suman Kumar Roy, Anup Kumar Bhattacharjee ${ }^{1}$, Chandrani Chakraborti ${ }^{2}$, Ritesh Singh}

Department of Community Medicine, College of Medicine and JNM Hospital, Kalyani, Nadia, ${ }^{2}$ Department of Nutrition, Swarupganj Pansila Balika Vidyalaya, Nabadwip, West Bengal, ${ }^{1}$ Department of Medicine, MGM Medical College and LSK Hospital, Kishanganj,

Bihar, India

Address for the Correspondence: Dr. Ritesh Singh, Department of Community Medicine, College of Medicine and JNM Hospital, Kalyani - 741235 , Nadia, West Bengal, India. E-mail: drriteshisngh@yahoo.com

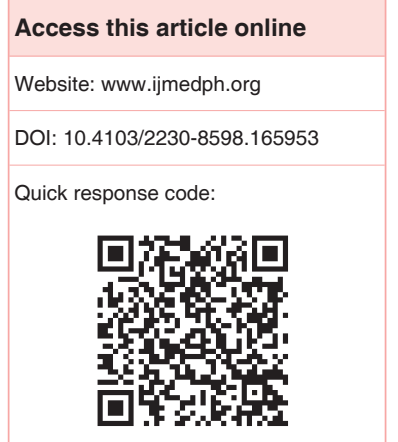

Background: The complaint of insomnia is one of the most common symptoms a physician encounters in his/her day-to-day practice. Though rarely present as the stand-alone problem, it accompanies other organic or psychological symptoms. Its incidence is on the rise in ever increasing stressful life of present times. Objectives: The objective was to study the prevalence and some sociodemographic factors associated with insomnia among the urban population of Kamarhati municipal area of district 24 Parganas (N) of the state West Bengal. Materials and Methods: The study was carried out at "Kamarhati" municipal area. Ten percent of householders of two randomly selected wards were surveyed. Self-reported sleep questionnaire insomnia symptoms questionnaire (ISQ) was administered to all adult members. Persons with a history of major psychiatric illness, regular shift work, daily alcohol consumption more than four units and on chemotherapy or radiotherapy were excluded from the survey. Results: ISQ identified $15.4 \%$ prevalence of insomnia. It was high in persons with co-morbid chronic physical illness $(28.1 \%)$ compared to persons free from that $(10.9 \%)(P<0.001)$. Insomnia was significantly higher among people living in joint families than those living in a nuclear family. The prevalence of insomnia increases significantly with the increasing age $(P<0.05)$. Conclusion: Findings of this study showed that the prevalence of insomnia in urban India is high. Increased life expectancy, increased burden of chronic illnesses, changing lifestyle, uncertainty of urban life contributes to high prevalence of insomnia that in turn affects quality of life.

Key words: Insomnia, insomnia symptom questionnaire, prevalence

\section{INTRODUCTION}

Insomnia is a highly disturbing condition. According to fourth edition of diagnostic and statistical manual (DSM-IV), insomnia is associated with complaints about the quality, quantity or timing of sleep at least 3 times a week and for at least 1 month. ${ }^{[1]}$ The international classification of sleep disorders, version 2 provides relevant diagnostic, and epidemiological information on sleep disorders to differentiate between the disorders. The ICSD-2 classification lists 81 major sleep disorder diagnostic categories in 8 major categories, each presented in detail, with a descriptive diagnostic text that includes specific diagnostic criteria. In addition, there are 13 diagnostic items listed in the appendices that include sleep disorders associated with disorders classified elsewhere, and psychiatric disorders frequently encountered in the differential diagnosis of sleep disorders. ${ }^{[2]}$

Approximately, one-third to one-fourth of the population in industrialized countries reported problems of sleep disturbances at some point of their lives and approximately $10 \%$ of the population suffer from persistent insomnia. ${ }^{[3]}$ Insomnia is one of the most common complaints in primary care setting. Studies around the world among general population showed that the prevalence of insomnia ranges between $10 \%$ and $48 \% \cdot{ }^{[4-6]}$ Much of this variation of prevalence may be explained by the use of different definitions of insomnia in those studies. ${ }^{[3]}$ Insomnia can have important consequences for sufferers and may affect health, work, and quality of life. Such associations include the development of depression, ${ }^{[4]}$ increased use of health care services ${ }^{[6,7]}$ and a higher risk of motor vehicle accidents. ${ }^{[8]}$ Several studies looking at the relationship between insomnia and work have found associations with absenteeism from 
work, decreased concentration, impaired work performance, and work-related accidents. ${ }^{[7,9]}$ Cross-sectional epidemiological studies have found that female sex especially peri-menopausal women, ${ }^{[10]}$ increased age, mental health problem, ${ }^{[1]}$ chronic medical conditions to be associated with higher prevalence of insomnia. However, most of these studies were conducted in developed world. Studies from developing countries in this regard are scarcely available in the literature. In developing countries like India, prevalence and risk factors of insomnia are not well studied. With this view in mind, this research was undertaken to study the prevalence and find out any relationship with sociodemographic characteristics of insomnia in an urban area of West Bengal, India.

\section{MATERIALS AND METHODS}

\section{Sampling frame}

The study was carried out at "Kamarhati Municipality" area, of district 24 Parganas (N), of state West Bengal, India. Based on available literature, sample size was calculated as 1152 (taking 25\% prevalence with absolute error of $2.5 \%$, i.e., relative error of $10 \%$ ). From two randomly selected wards, $10 \%$ of households were selected using systematic random sampling. All adult members of selected households constituted sample population.

\section{Period of study}

The period of survey was from March 2011 to August 2011.

\section{Study population}

One thousand one hundred and eighty-five eligible subjects were included in this study.

\section{Exclusion criteria}

These group of persons was excluded from the study: Person below 16 years and above 65 years of age as because they have much higher sleep problem secondary to medical conditions associated with old age, anyone suffering from any major psychiatric illness, persons engaged in regular shift work and regular heavy drinker $>4$ unit of alcohol per day).

\section{Study instrument and technique}

The Insomnia symptom questionnaire is a 13-item self-reported instrument designed to identify insomnia. ${ }^{[12]}$ Insomnia symptoms questionnaire (ISQ) questions are based on American psychiatric association's DSM-IV criteria and are consistent with the American Academy of Sleep Medicine's research and diagnostic criteria. Apart from ISQ, another pretested schedule was used to collect sociodemographic data. Following sociodemographic data were collected: Age, sex, occupation, education, etc. For education, number of years spent in a formal school was taken. The education was further divided as low and high depending on the number of years spent in the school. The cut-off was taken arbitrarily as 10 years. The questionnaire was prepared in English and then translated in the local language, Bengali. The translated questionnaire was pretested in 20 individuals eligible for the study. These individuals were not taken for analysis purpose. The final corrections were made in the questionnaire. The questionnaire was then back translated in the English language to see whether the meaning of the question changed due to translation. The relevant data from each member of household were collected through face-to-face interview technique. ISQ was administered to all members.

\section{Ethical considerations}

The permission to conduct the study was taken from the Institutional Ethics Committee of the College of Medicine and JNM Hospital, Kalyani. The informed consent form was designed in such a way that the participant understands it and was in the local language, Bengali. Written informed consent was taken from each participant before the administration of the questionnaire. No personal identifier was collected. Identity of the participants was never at stake.

\section{Data analysis}

Data analysis was done with the help of Epi-info ${ }^{\text {TM }}$ (CDC, Atlanta) version 6 Software. Appropriate statistical tests were applied. All tests were two-tailed and $P<0.05$ was considered to be statistically significant.

\section{RESULTS}

The mean age of the sample population $(n=1185)$ was 44.5 years with standard deviation (SD) \pm 11.08 years. Among participants, $48.5 \%$ are female and $51.5 \%$ are male. Overall prevalence of insomnia in this study was $15.4 \%$. The percentage of female with insomnia was a little higher than that of male $(16.9 \%$ and $14.1 \%$ respectively). However, this difference is not statistically significant. In the 40-50 years of age group that corresponds to perimenopausal period in women, insomnia prevalence was significantly higher among female than male participants.

Prevalence of insomnia was found to be increasing with advancing age. Highest prevalence was observed in the age group of $>60$ years (20.2\%) followed by $50-60$ years and $40-50$ years of age group (18.2\% and $17.3 \%$ respectively). Advancing age and prevalence of insomnia was found to be significantly associated (Chi-square-13.49, df-5, P-0.019).

Marital status, tobacco addiction, educational level, body mass index (BMI), family type, and presence of chronic organic illness of all participants were compared to the presence of insomnia symptoms [Table 1]. Insomnia was found to be significantly higher among participants with BMI $\geq 25$ (Chi-square-38.75, P-0.0000), who used tobacco regularly (Chi-square-7.61, $P$-0.005), belonged to joint family (Chi-square-29.29, P-0.0000), and also among sufferers of chronic organic disease (Chi-square-48.14, $P$-0.0000).

Mean years of education of the participants was 6.6 years with SD of \pm 4.1 years. In this study, educational status of "high" and "low" 


\begin{tabular}{|c|c|c|}
\hline Variable & Insomnia present (\%) & $X^{2}, P$ \\
\hline \multicolumn{3}{|l|}{ Sex } \\
\hline Male & $97(16.9)$ & $1.74,0.18$ \\
\hline Female & $86(14.1)$ & \\
\hline \multicolumn{3}{|l|}{ Age group (in years) } \\
\hline$<30$ & $08(7.5)$ & $12.92,0.017$ \\
\hline $30-40$ & $45(13.2)$ & \\
\hline $41-50$ & $64(17.3)$ & \\
\hline $51-60$ & $47(18.2)$ & \\
\hline$>60$ & $19(20.2)$ & \\
\hline \multicolumn{3}{|l|}{ BMI } \\
\hline$<25$ & $113(12.1)$ & $38.75,0.0000$ \\
\hline$\geq 25$ & $70(28.1)$ & \\
\hline \multicolumn{3}{|l|}{ Marital status } \\
\hline Single & $18(9)$ & $25.55,0.0000$ \\
\hline Married & $143(15.5)$ & \\
\hline Divorced/widow & $22(35.5)$ & \\
\hline \multicolumn{3}{|l|}{ Family type } \\
\hline Joint & $124(21.2)$ & $29.29,0.0000$ \\
\hline Nuclear & $59(9.8)$ & \\
\hline \multicolumn{3}{|c|}{ Chronic medical illness } \\
\hline Present & $87(27.7)$ & $48.14,0.0000$ \\
\hline Not present & $96(11.1)$ & \\
\hline \multicolumn{3}{|l|}{ Education } \\
\hline Low (<10 years) & $101(18.1)$ & $5.58,0.01$ \\
\hline High ( $\geq 10$ years) & $82(13.1)$ & \\
\hline \multicolumn{3}{|l|}{ Tobacco use } \\
\hline User & $94(18.8)$ & $7.61,0.000$ \\
\hline Nonuser & $89(13)$ & \\
\hline
\end{tabular}

$\mathrm{BMI}=$ Body mass index

was taken according to years spent at school. "High" was defined as longer than 10 years of education and "low" as $\leq 10$ years of education. In this study, insomnia was significantly more among people with low education (Chi-square-5.58, P-0.01).

Prevalence of insomnia was higher among married and highest among divorce/widowed, than the unmarried person (9\% among unmarried, $15.5 \%$ among married, and 35.5\% among divorce/widowed) which is significant.

Regarding care seeking behavior, $43.2 \%$ of insomniac persons never seek medical advice for insomnia, whereas $15.3 \%$ consulted a doctor for their problem. $32.2 \%$ of the persons identified as suffering from insomnia said that they went to the physician for some other complaint and told the physician about the insomnia during the consultation. Nearly 10\%, if the insomniac were taking self-medication for their sleep disturbances. This indicate that sleep disorder as a medical problem is not being given due importance by the population.

\section{DISCUSSION}

We use ISQ in this study because of distinctive quality of ISQ is that it not only measures the severity of insomnia, but it is also an instrument that appears to provide an accurate case definition of insomnia. ${ }^{[1]}$

Overall, the prevalence of insomnia as identified through ISQ was $15.4 \%$. This observation corroborated with previous studies. ${ }^{[4,5]}$ This implicate that the prevalence of insomnia in urban India is no less than the developed world. In this study, the prevalence of insomnia increases with age and was found statistically significant. Some studies reported a link between increasing age and prevalence of insomnia, ${ }^{[6,12]}$ but this finding was not consistent. ${ }^{[13,14]}$ While comparing the prevalence of insomnia up to 40 years of age group to above 40 years of age group, the difference was found significant (Chi-square-9.44, $P=0.002$ ). This indicates that subjects with insomnia showed a peak after 40 years of age.

Though many studies showed a significant association between female sex and insomnia, ${ }^{[3,15]}$ our study showed no significant association between female sex and insomnia. However, among perimenopausal women (40-50 years) prevalence of insomnia was found significantly higher than a male of similar age group. This observation corroborated with previous studies. ${ }^{[16]}$

Observations that insomnia is found significantly higher among smokers, persons with high $(\geq 25) \mathrm{BMI}$, low level of education, and persons with chronic medical illness corroborates with previous studies. ${ }^{[13,17]}$

One interesting observation of this study is that the prevalence of insomnia was found significantly higher among persons living in joint family. It may be due to rapid change of traditional social values, rapid urbanization, and economic differences between members of joint families. The lack of individual space or overcrowding in the house may explain the higher prevalence of insomnia in joint families. These issues need further study.

Regarding care seeking behavior, it was observed in the present study that only around $15 \%$ of subjects having insomnia consulted a doctor for this problem. It indicates that the majority of people do not consider insomnia as an important medical problem or are not aware of its chronic consequences. Awareness about insomnia is still poor among the general population as well as medical practitioners in developing country.

\section{CONCLUSION}

This study provides some idea about prevalence and sociodemographic characteristics of insomnia in urban India. Overall prevalence of insomnia $(15.4 \%)$ is comparable with the developed world. Like other studies in different parts of world, present study also showed statistical association between insomnia and advancing age, BMI $(>25)$, marital status, smoking habit, peri-menopausal women, and presence of chronic medical illness. Apart from that, this study also showed a significant association between joint family and prevalence of insomnia. However, larger epidemiological studies are needed to understand the complete epidemiology of insomnia 
in developing world.

\section{Limitation of study}

One important limitation of this study, which is also the limitation of the tool we used, is inability to classify the insomnia as primary or secondary.

\section{ACKNOWLEDGMENT}

We express our heartiest gratitude to the respondents for taking part in the interviews, trustees of "Foundation for Developmental Challenges and Social Research" for funding this study and Mr. Santanu Mallick for data entry and computer works.

\section{REFERENCES}

1. American Psychiatric Association. Diagnostic and Statistical Manual of Mental Disorder. $4^{\text {th }}$ ed. Washington, D.C: American Psychiatric Association; 1994. p. 557.

2. Thorpy MJ. Classification of sleep disorders. Neurotherapeutics 2012;9:687-701.

3. Ohayon MM. Epidemiology of insomnia: What we know and what we still need to learn. Sleep Med Rev 2002;6:97-111.

4. Ford DE, Kamerow DB. Epidemiologic study of sleep disturbances and psychiatric disorders. An opportunity for prevention? JAMA 1989;262:1479-84.

5. Quera-Salva MA, Orluc A, Goldenberg F, Guilleminault C. Insomnia and use of hypnotics: Study of a French population. Sleep 1991;14:386-91.

6. Weyerer S, Dilling H. Prevalence and treatment of insomnia in the community: Results from the Upper Bavarian Field Study. Sleep 1991;14:392-8.

7. Léger D, Guilleminault C, Bader G, Lévy E, Paillard M. Medical and socio- professional impact of insomnia. Sleep 2002;25:625-9.

8. Ohayon MM, Smirne S. Prevalence and consequences of insomnia disorders in the general population of Italy. Sleep Med 2002;3:115-20.

9. Linton SJ, Bryngelsson IL. Insomnia and its relationship to work and health in a working-age population. J Occup Rehabil 2000;10:169-83.

10. Kravitz HM, Ganz PA, Bromberger J, Powell LH, Sutton-Tyrrell K, Meyer PM. Sleep difficulty in women at midlife: A community survey of sleep and the menopausal transition. Menopause 2003;10:19-28.

11. Morphy H, Dunn KM, Lewis M, Boardman HF, Croft PR. Epidemiology of insomnia: A longitudinal study in a UK population. Sleep 2007;30:274280.

12. Okun ML, Kravitz HM, Sowers MF, Moul DE, Buysse DJ, Hall M. Psychometric evaluation of the Insomnia Symptom Questionnaire: A self-report measure to identify chronic insomnia. J Clin Sleep Med 2009;5:41-51.

13. Aslan S, Gulcat Z, Selda Albayrak F, Maral I, Yetkin S, Sutcigil L, et al. Prevalence of insomnia symptoms: Results from an urban district in Ankara, Turkey 1. Int J Psychiatry Clin Pract 2006;10:52-8.

14. Leger D, Guilleminault C, Dreyfus JP, Delahaye C, Paillard M. Prevalence of insomnia in a survey of 12,778 adults in France. J Sleep Res 2000;9:35-42.

15. Ohayon M. Epidemiological study on insomnia in the general population. Sleep 1996;19 3 Suppl:S7-15.

16. Klink M, Quan SF. Prevalence of reported sleep disturbances in a general adult population and their relationship to obstructive airways diseases. Chest 1987;91:540-6.

17. Sharma SK. Wake-up call for sleep disorders in developing nations. Indian J Med Res 2010;131:115-8.

How to cite this article: Roy SK, Bhattacharjee AK, Chakraborti $C$, Singh R. Prevalence of insomnia in urban population of West Bengal: A community-based cross-sectional study. Int J Med Public Health 2015;5:293-6.

Source of Support: Nil, Conflict of Interest: None declared. 